\title{
Non-Covalent Self-Assembly of Protein Crystals with Tunable Structures
}

\author{
Mingming Du, ${ }^{\dagger \neq}$ Kun Zhou, ${ }^{*}$ Runze Yu, ${ }^{\S}$ Yufeng Zhai, ${ }^{\S}$ Gang Chen ${ }^{\S}$ and Qiangbin Wang ${ }^{\square, \dagger, *,}$
}

${ }^{\dagger}$ School of Nano-Tech and Nano-Bionics, University of Science and Technology of China, Hefei

230026, China

${ }^{\ddagger}$ CAS Key Laboratory of Nano-Bio Interface, Division of Nanobiomedicine and $i$-Lab, Suzhou Institute of Nano-Tech and Nano-Bionics, Chinese Academy of Sciences, Suzhou 215123, China

$\S$ School of Physical Science and Technology, ShanghaiTech University, Shanghai 201210, China

\section{Method}

Preparation of RhuA plasmids: All RhuA variants including ${ }^{\mathrm{H} 47} \mathrm{RhuA}-\mathrm{C}(2 \mathrm{H})$, ${ }^{\mathrm{H} 47 / \mathrm{H} 157} \mathrm{RhuA}-\mathrm{C}(2 \mathrm{H})-\mathrm{N}(2 \mathrm{H})$, and ${ }^{\mathrm{D} 47} \mathrm{RhuA}$ were constructed through site-directed mutagenesis and cloned into pET-32a expression vectors. These variants all contain the mutations of E192A and C126S as previously reported. ${ }^{1,2}$ The mutations were verified by sequencing (Shanghai Invitrogen Biotechnology Co., Ltd.) and transformed into Escherichia coli (E. coli) BL21 (DE3) strain (Novagen) for protein expression.

Expression, purification and self-assembly of Recombinant RhuA: ${ }^{\mathrm{H} 47} \mathrm{RhuA}-\mathrm{C}(2 \mathrm{H})$ protein expression was induced by the addition of final $0.6 \mathrm{mM}$ isopropyl $\beta$-D-1thiogalactopyranoside (IPTG) with shaking at $200 \mathrm{rpm}, 27^{\circ} \mathrm{C}$ for $14 \mathrm{~h}$. For the ${ }^{\mathrm{D} 47} \mathrm{RhuA}$ expression, final $0.6 \mathrm{mM}$ IPTG with shaking at $200 \mathrm{rpm}, 27^{\circ} \mathrm{C}$ for $14 \mathrm{~h}$ was executed, while for the ${ }^{\mathrm{H} 47 / \mathrm{H} 157} \mathrm{RhuA}-\mathrm{C}(2 \mathrm{H})-\mathrm{N}(2 \mathrm{H})$ expression, we used lower IPTG concentration of $0.1 \mathrm{mM}$ with shaking at $200 \mathrm{rpm}, 16^{\circ} \mathrm{C}$ for $14 \mathrm{~h}$. The harvested cells were resuspended using $10 \mathrm{mM}$ Tris buffer ( $\mathrm{pH}$ 7.5) and subjected to sonication on ice. After centrifugation of cell lysis for $30 \mathrm{~min}$ at $12000 \mathrm{rpm}$ at $4^{\circ} \mathrm{C}$, the supernatant was collected. Purification process was then performed according to a previously reported method with minor modifications. ${ }^{3,4}$ Briefly, the ammonium sulfate was added into the solution containing RhuA variants at a final concentration of $1.7 \mathrm{M}$, followed by centrifugation at $12000 \mathrm{rpm}, 4^{\circ} \mathrm{C}$ for $30 \mathrm{~min}$. The precipitate was collected, dissolved in $10 \mathrm{mM}$ Tris buffer (pH 7.5) and then dialyzed against same buffer solution to remove residual ammonium sulfate. Further purification was conducted on a HiTrap ${ }^{\mathrm{TM}}$ Q HP 
column (GE Healthcare; at $\mathrm{pH}$ 8.0) using a 0-500 $\mathrm{mM} \mathrm{NaCl}$ gradient elution. Pure protein fractions were eluted at $250 \mathrm{mM} \mathrm{NaCl}$ and dialyzed against $10 \mathrm{mM}$ Tris buffer $(\mathrm{pH} 7.5)$ to remove $\mathrm{NaCl}$, and then concentrated using a $10 \mathrm{kD}$ cut-off centrifugal filter at $4^{\circ} \mathrm{C}$. Purity was confirmed by SDS-PAGE and proteins were stored at $-80^{\circ} \mathrm{C}$.

Self-assembly of 3D nanoribbons and 3D protein crystals: $7 \mathrm{mg} / \mathrm{mL}$ of ${ }^{\mathrm{H}}{ }^{4} \mathrm{RhuA}-$ $\mathrm{C}(2 \mathrm{H})$ proteins were exchanged into freshly prepared MOPS buffer $(20 \mathrm{mM}, \mathrm{pH} 6.5)$. The samples were kept at $12^{\circ} \mathrm{C}$ for $12 \mathrm{~h}$ for the formation of $3 \mathrm{D}$ nanoribbons. The protein crystals were confirmed by using TEM. Then the remaining samples were kept at $12^{\circ} \mathrm{C}$ for additional 3 days for the formation of $3 \mathrm{D}$ protein crystals, which were characterized by TEM, AFM, SAXS and Multichannel NIR-II fluorescence microscope. To tune the $\mathrm{pH}$-dependent crystal morphology, the 3D crystal samples within pH 6.5 MOPS buffer were dialyzed against $20 \mathrm{mM} \mathrm{pH} 2.8$ MOPS for $3 \mathrm{~h}$. After incubation, the samples were centrifuged at $12000 \mathrm{rpm}$ for $12 \mathrm{~min}$ at $4^{\circ} \mathrm{C}$. The precipitate was removed, and the supernatant were characterized by TEM. The treated sample were exchanged with $20 \mathrm{mM}$ pH 6.5 MOPS buffer again by dialysis for 3-5 days. After incubation, the transparent crystals were obtained and characterized by TEM, AFM and SAXS and fluorescence microscope.

Self-assembly of 3D protein crystals mediated by $\mathbf{Z n}^{2+}: 1 \mathrm{mg} / \mathrm{mL}$ of ${ }^{\mathrm{H} 47} \mathrm{RhuA}-\mathrm{C}(2 \mathrm{H})$ proteins were exchanged into freshly prepared $20 \mathrm{mM} \mathrm{pH} 6.5$ MOPS containing $25 \mu \mathrm{M}$ $\mathrm{ZnCl}_{2}$. The samples were kept at $12^{\circ} \mathrm{C}$ for $6 \mathrm{~h}$ for the formation of $3 \mathrm{D}$ protein crystals. The protein crystals were characterized by TEM, AFM and SAXS and fluorescence microscope. The samples were further dialyzed against $20 \mathrm{mM} \mathrm{pH} 7 \mathrm{MOPS}$ buffer with $10 \mathrm{mM}$ EDTA for $3 \mathrm{~h}$. After incubation, the samples were centrifuged at $12000 \mathrm{rpm}$ for $12 \mathrm{~min}$ at $4^{\circ} \mathrm{C}$. The precipitate was removed, and the supernatant were verified by TEM. The treated sample were dialyzed to remove EDTA and then incubated in a buffer (20 $\mathrm{mM}$ MOPS, $\mathrm{pH} 6.5,25 \mu \mathrm{M} \mathrm{ZnCl}_{2}$ ). After incubation, the crystals were obtained and characterized by TEM, AFM and SAXS and fluorescence microscope.

Self-assembly of double-helical superstructures: $0.5 \mathrm{mg} / \mathrm{mL}$ of ${ }^{\mathrm{H} 47 / \mathrm{H} 157} \mathrm{RhuA}-\mathrm{C}(2 \mathrm{H})$ $\mathrm{N}(2 \mathrm{H})$ proteins were exchanged into freshly prepared $20 \mathrm{mM} \mathrm{pH} 7.5 \mathrm{MOPS}$. The 
samples were kept at $12^{\circ} \mathrm{C}$ for 3 days for the formation of double-helical superstructures. The protein crystals were confirmed by TEM.

TEM Characterization: $10 \mu \mathrm{L}$ aliquots of crystal suspensions were applied onto negatively glow-discharged carbon-coated copper grids. Suspensions which failed to adsorb on the grids were washed away with Mill-Q water. The grids were then stained with $1 \%$ uranyl acetate and cleaned right afterwards. Corresponding images were obtained using a FEI Tecnai 20 TEM operating at $200 \mathrm{kV}$. Images for analysis were collected with a Gatan Ultra Scan 894 CCD camera and processed with ImageJ software.

AFM Characterization: $5 \mu \mathrm{L}$ aliquots of samples were applied on freshly cleaved mica, washed with deionized water, and then dried. AFM images were collected using a Dimension Icon microscope (Bruker) using Scan Asyst peak force tapping (in air) mode at a resolution of 512 lines per image and a scan rate of $0.5-1.0 \mathrm{~Hz}$. The AFM images obtained were processed using Nanoscope Analysis (Bruker).

SAXS Characterization: The SAXS experiments were performed at beamline BL16B1 and BL19U2 of Shanghai Synchrotron Radiation Facility (SSRF). The incident X-ray photon energy was $10 \mathrm{keV}$ (wavelength $=0.124 \mathrm{~nm}$ ) and $12 \mathrm{keV}$ (wavelength $=0.103 \mathrm{~nm}$ ), and the distance between the sample and the detector was set to 2.09 and $2.62 \mathrm{~m}$, respectively. During the experiments, each solution $(\sim 100 \mu \mathrm{L})$ was sealed into a $2 \mathrm{~mm}$-thick Teflon cell with two thin Kapton windows. Two-dimensional SAXS patterns were collected using Pilatus detector with a pixel size of $172 \mu \mathrm{m} \times 172$ $\mu \mathrm{m}$. One-dimensional SAXS curves were obtained by integrating along the equal wavevector transferring rings using FIT2D software package.

Fluorescence microscope characterization: For thioflavin-T emission experiments $(E x=430 \mathrm{~nm} ; \mathrm{Em}=440-600 \mathrm{~nm})$, the prepared samples containing thioflavin-T $(10$ $\mu \mathrm{M})$ were applied on a clean glass slide and dried. Then, they were imaged by a fluorescence microscope. 

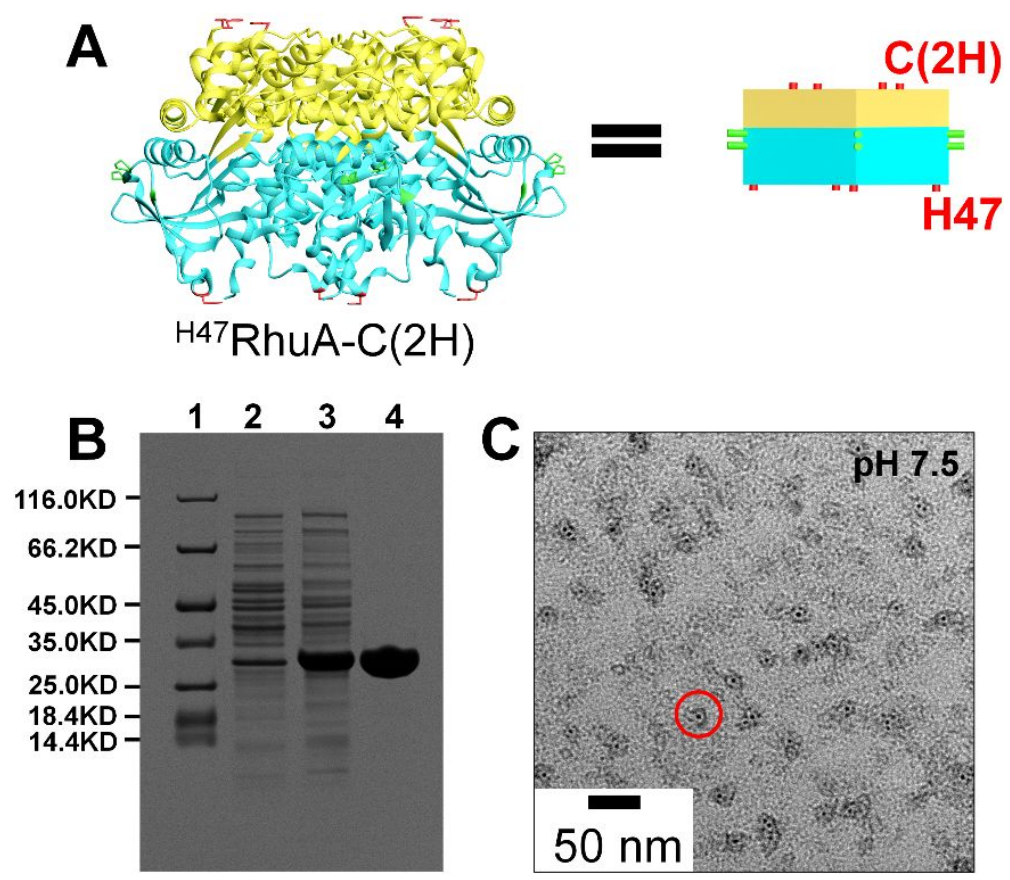

Figure S1. (A) The cartoon of ${ }^{\mathrm{H} 4}{ }^{\mathrm{R} h u A} \mathrm{C}(2 \mathrm{H})$ structure, the (B) SDS-PAGE, and the (C) TEM image of ${ }^{\mathrm{H} 47} \mathrm{RhuA}-$ $\mathrm{C}(2 \mathrm{H})$.
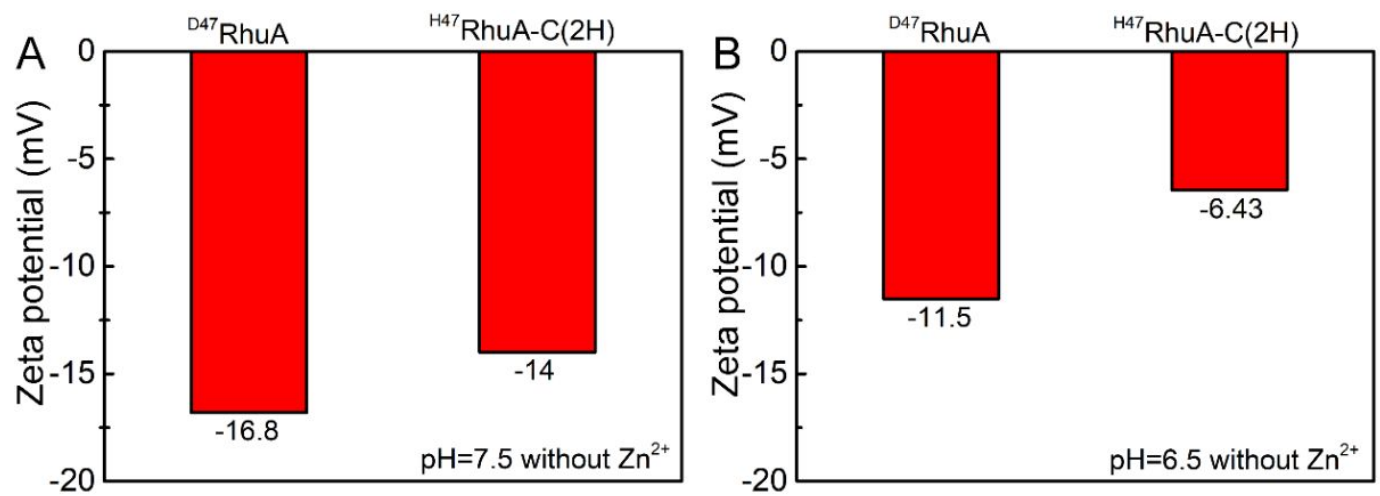

Figure S2. The characterization of zeta potential of ${ }^{\mathrm{H} 47} \mathrm{RhuA}-\mathrm{C}(2 \mathrm{H})$ and ${ }^{\mathrm{D} 47} \mathrm{RhuA}$ (control) tetramers at (A) $\mathrm{pH}=7.5$ and (B) $\mathrm{pH}=6.5$ without $\mathrm{Zn}$ ions. 

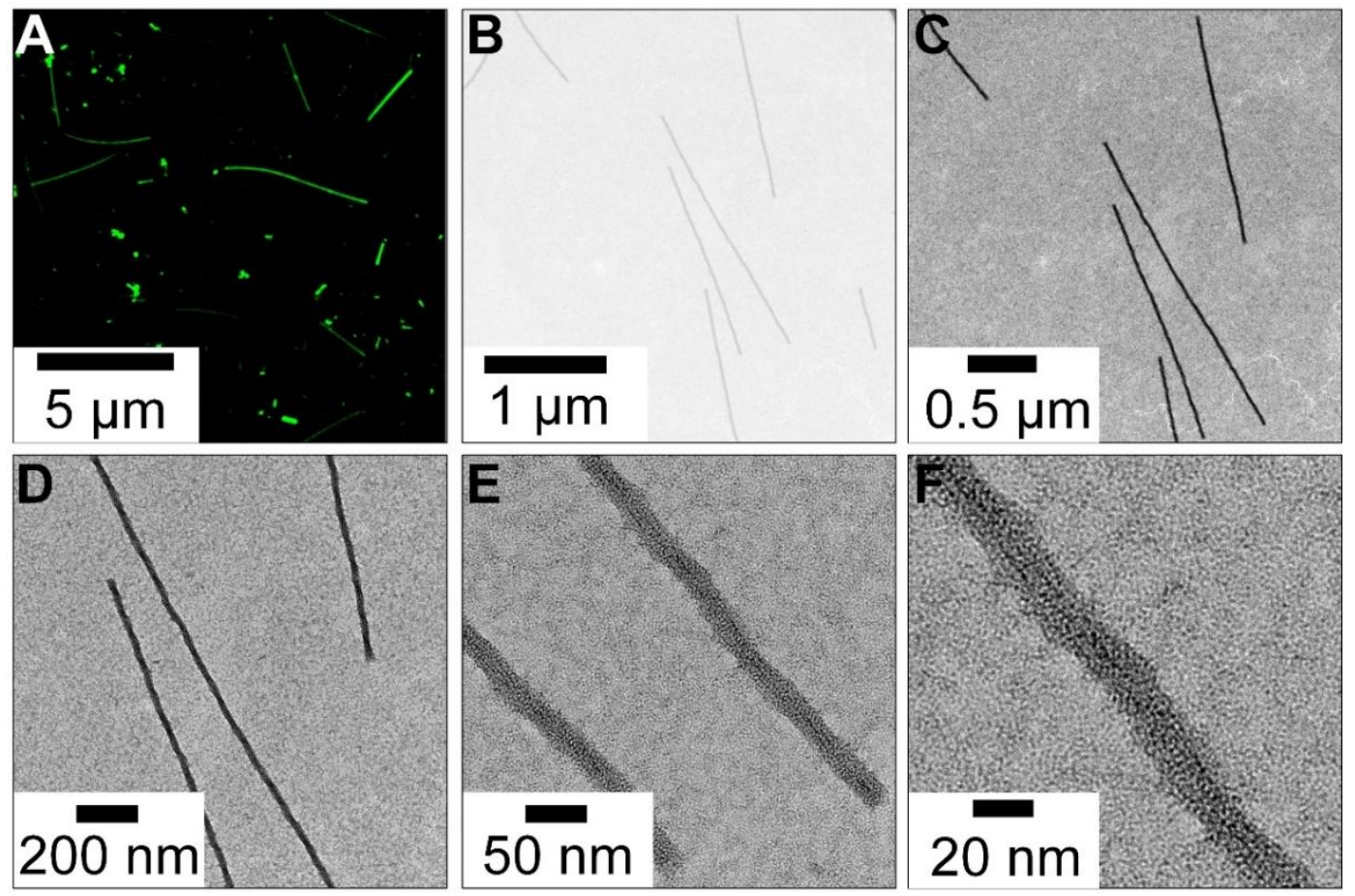

Figure S3. Additional structural characterization of 3D nanoribbons. (A) Fluorescence picture. (B-F) Low- and highresolution TEM images.
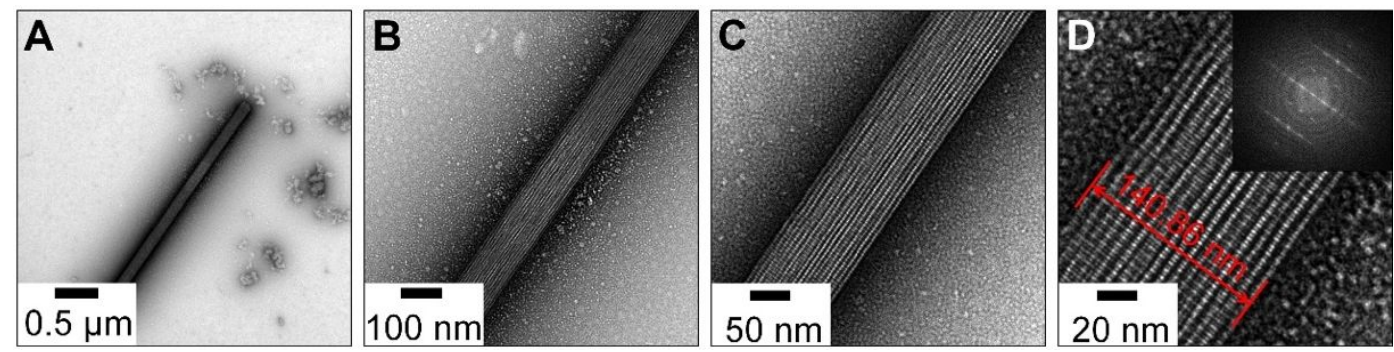

Figure S4. TEM characterization of an intermediate state of 3D nanoribbons to 3D crystal after incubation for one day more at $12{ }^{\circ} \mathrm{C}$. (A-D) Low- and high-resolution TEM images.
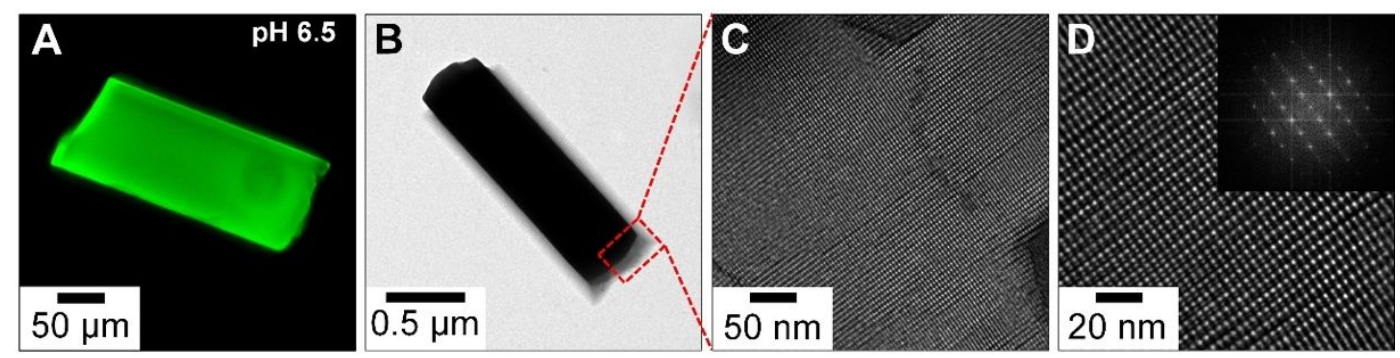

Figure S5. Additional structural characterization of 3D crystal mediated by non-covalent interactions. (A) Fluorescence picture. (B-D) Low- and high-resolution TEM images. 

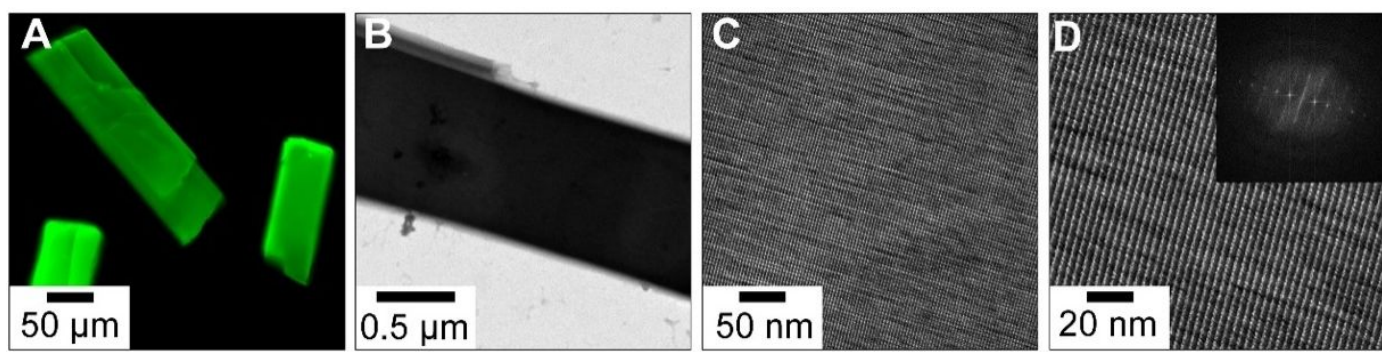

Figure S6. TEM characterization of 3D crystals mediated by non-covalent interactions after incubation for 15 days. (A) Fluorescence picture. (B-D) Low- and high-resolution TEM images.
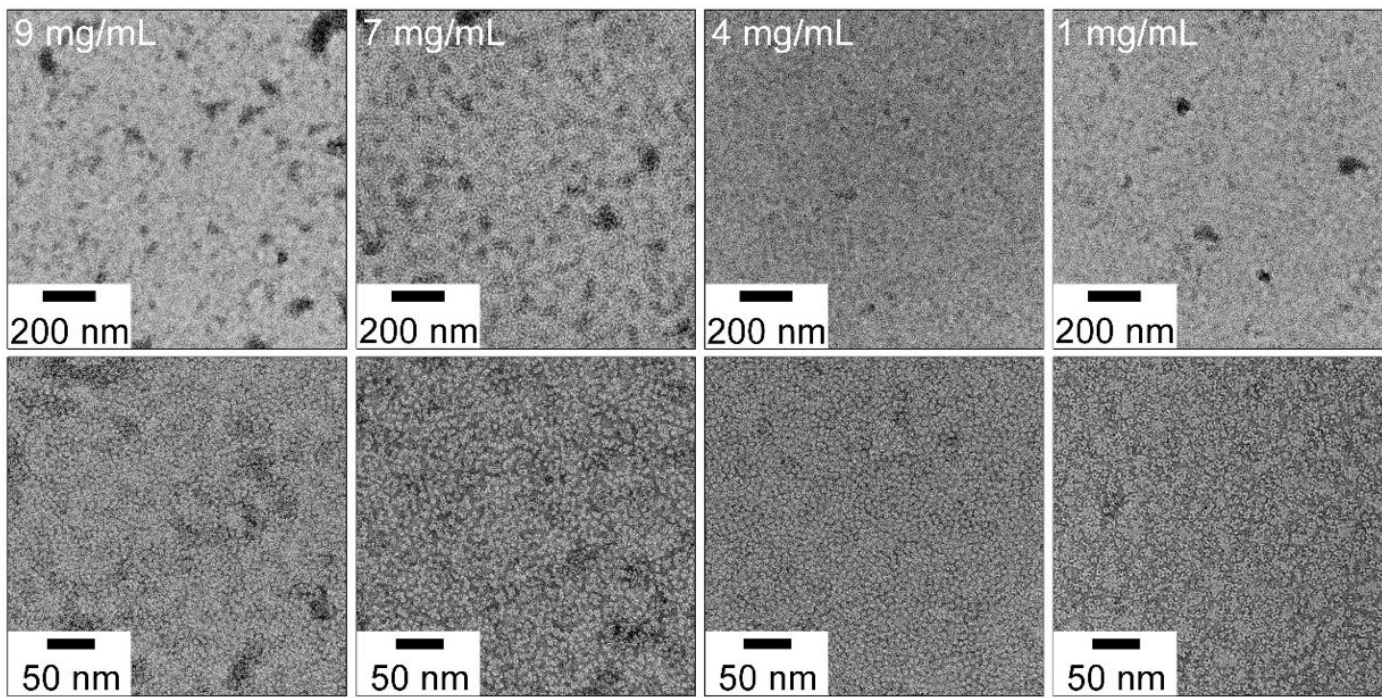

Figure S7. TEM characterization of ${ }^{\mathrm{D} 47} \mathrm{RhuA}$ with various concentrations under assembly condition (20 mM MOPS, pH 6.5, 3 days, $12{ }^{\circ} \mathrm{C}$ ) that were optimized for ${ }^{\mathrm{H} 47} \mathrm{RhuA}-\mathrm{C}(2 \mathrm{H})$; seen main text or Figure S3 and S5 for details.

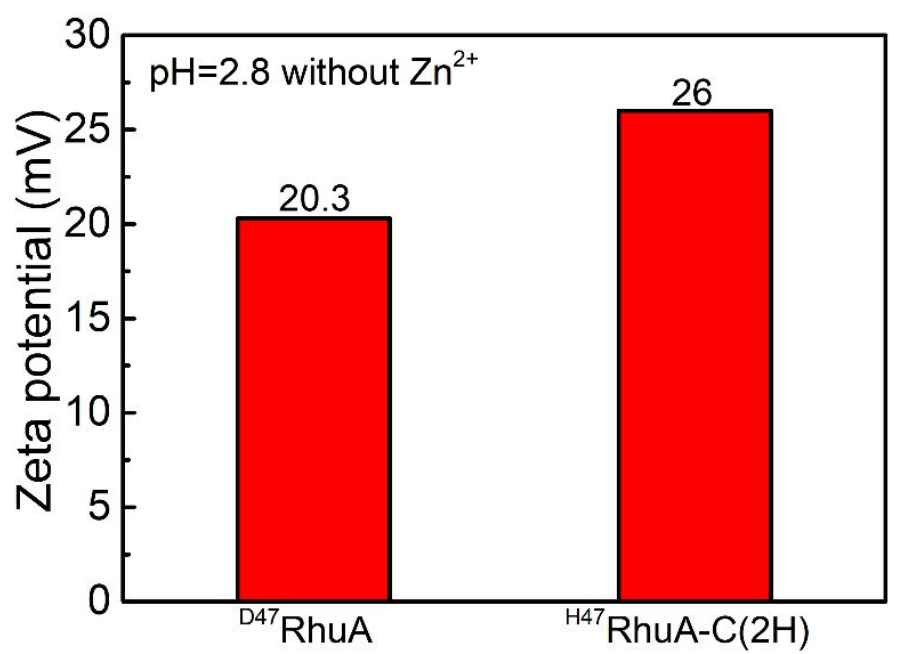

Figure S8. The characterization of zeta potential of ${ }^{\mathrm{H} 47} \mathrm{RhuA}-\mathrm{C}(2 \mathrm{H})$ and ${ }^{\mathrm{D} 47} \mathrm{RhuA}$ (control) tetramers at $\mathrm{pH}=2.8$ without $\mathrm{Zn}$ ions. 

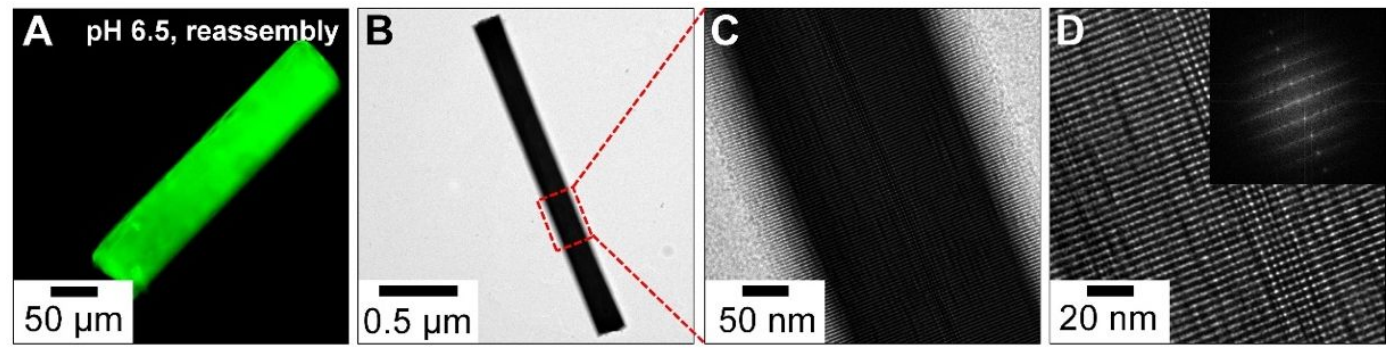

Figure S9. Additional structural characterization of reassembled 3D crystals mediated by non-covalent interactions. (A) Fluorescence picture. (B-D) Low- and high-resolution TEM images.
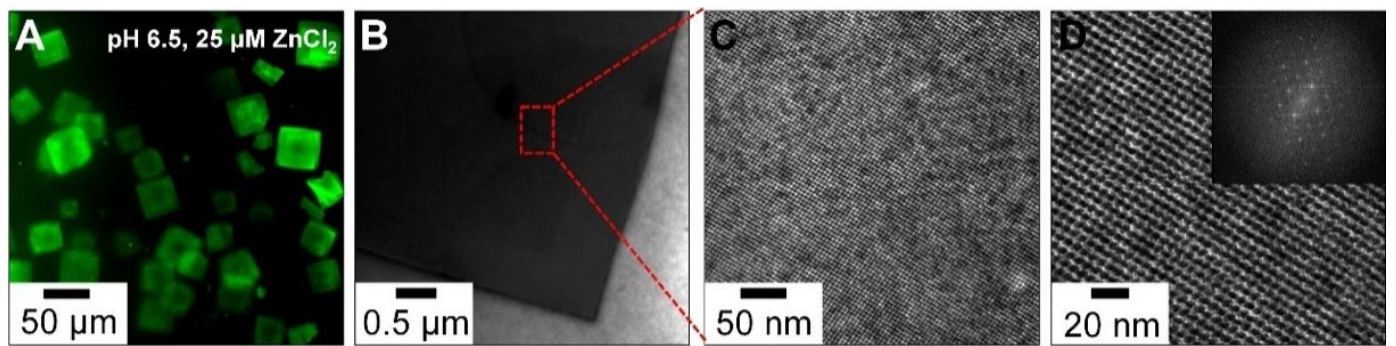

Figure S10. Additional structural characterization of 3D crystals mediated by $\mathrm{Zn}$ ions. (A) Fluorescence picture. (BD) Low- and high-resolution TEM images.

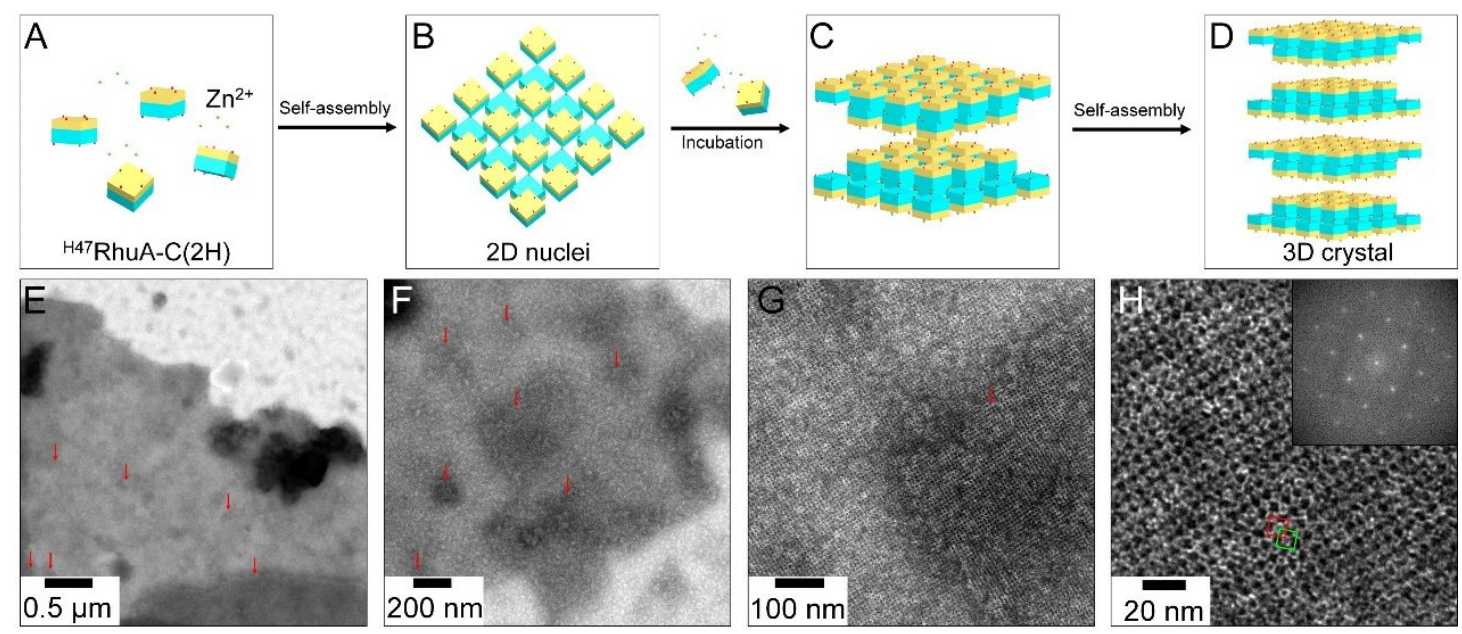

Figure S11. TEM characterization for the structural transition from 2D to 3D. (A-D) Scheme of the self-assembly process of ${ }^{\mathrm{H} 7} \mathrm{RhuA}-\mathrm{C}(2 \mathrm{H})$ directed by $\mathrm{Zn}^{2+}$-His interaction. (E-H) TEM images of the intermediate states. 

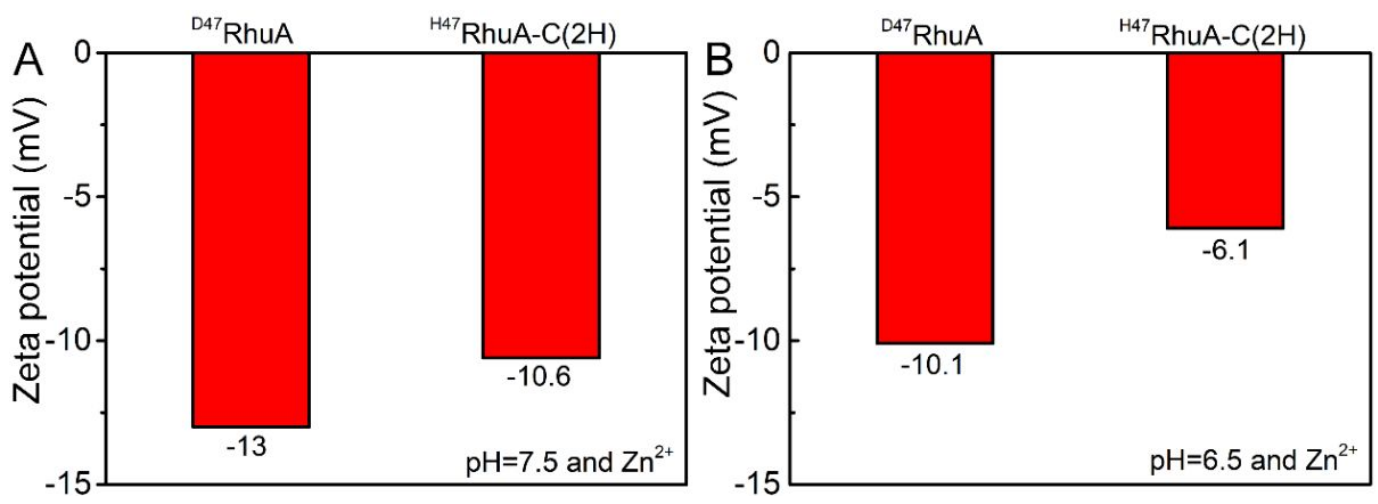

Figure S12. The characterization of zeta potential of ${ }^{447} \mathrm{RhuA}-\mathrm{C}(2 \mathrm{H})$ and ${ }^{\mathrm{D} 47} \mathrm{RhuA}$ (control) tetramers at (A) $\mathrm{pH}=$ 7.5 and $\mathrm{ZnCl}_{2}(25 \mu \mathrm{M})$, (B) $\mathrm{pH}=6.5$ and $\mathrm{ZnCl}_{2}(25 \mu \mathrm{M})$.
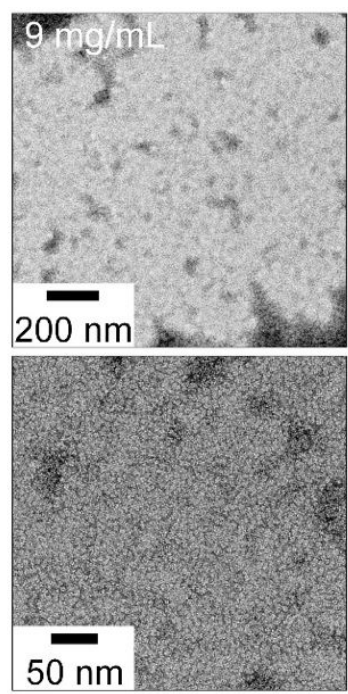
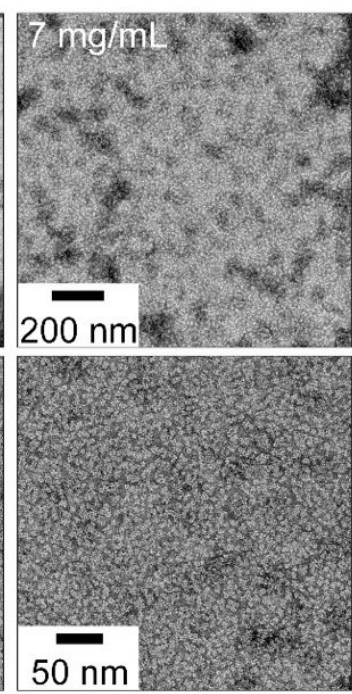
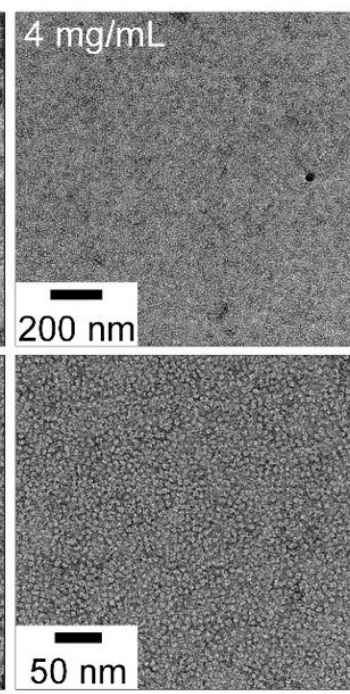
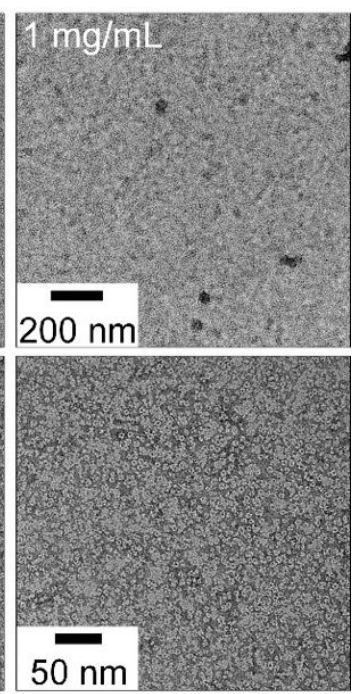

Figure S13. TEM characterization of ${ }^{\mathrm{D} 47} \mathrm{RhuA}$ with various concentrations under $\mathrm{Zn}^{2+}$-mediated self-assembly conditions (20 mM MOPS, pH 6.5, $25 \mu \mathrm{M} \mathrm{ZnCl}_{2}, 6 \mathrm{~h}, 12{ }^{\circ} \mathrm{C}$ ) that were optimized for ${ }^{\mathrm{H} 47} \mathrm{RhuA}-\mathrm{C}(2 \mathrm{H})$; seen main text or Figure S11 for details.
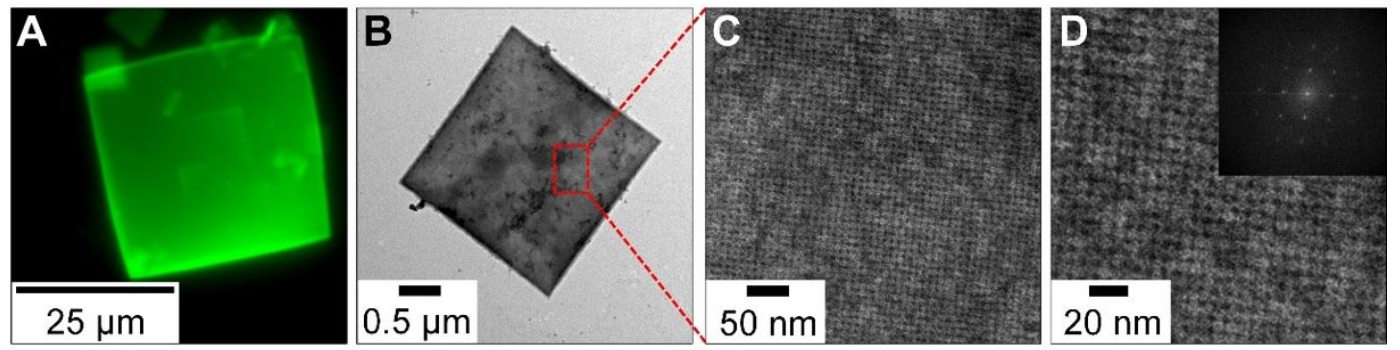

Figure S14. TEM characterization of 3D crystals mediated by Zn ions after incubation for 15 days. (A) Fluorescence picture. (B-D) Low- and high-resolution TEM images. 

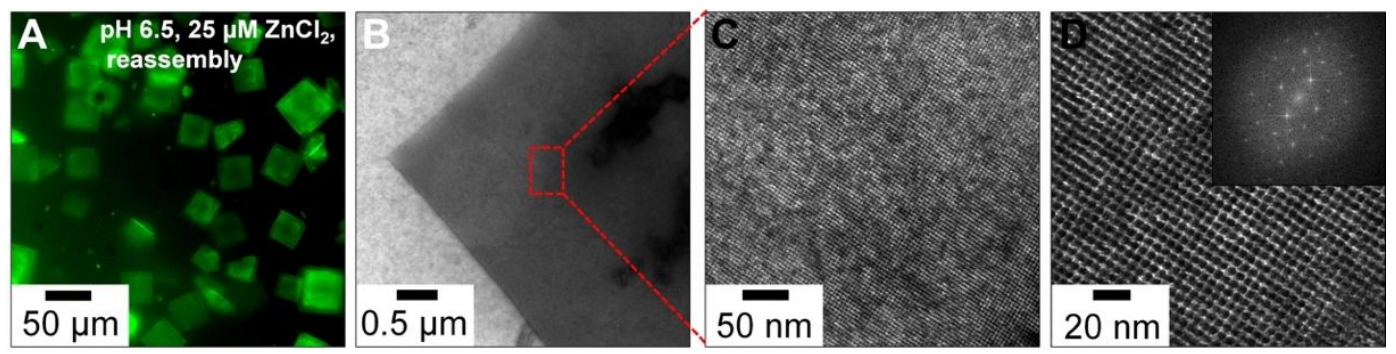

Figure S15. Additional structural characterization of reassembled 3D crystals mediated by Zn ions. (A) Fluorescence picture. (B-D) Low- and high-resolution TEM images.

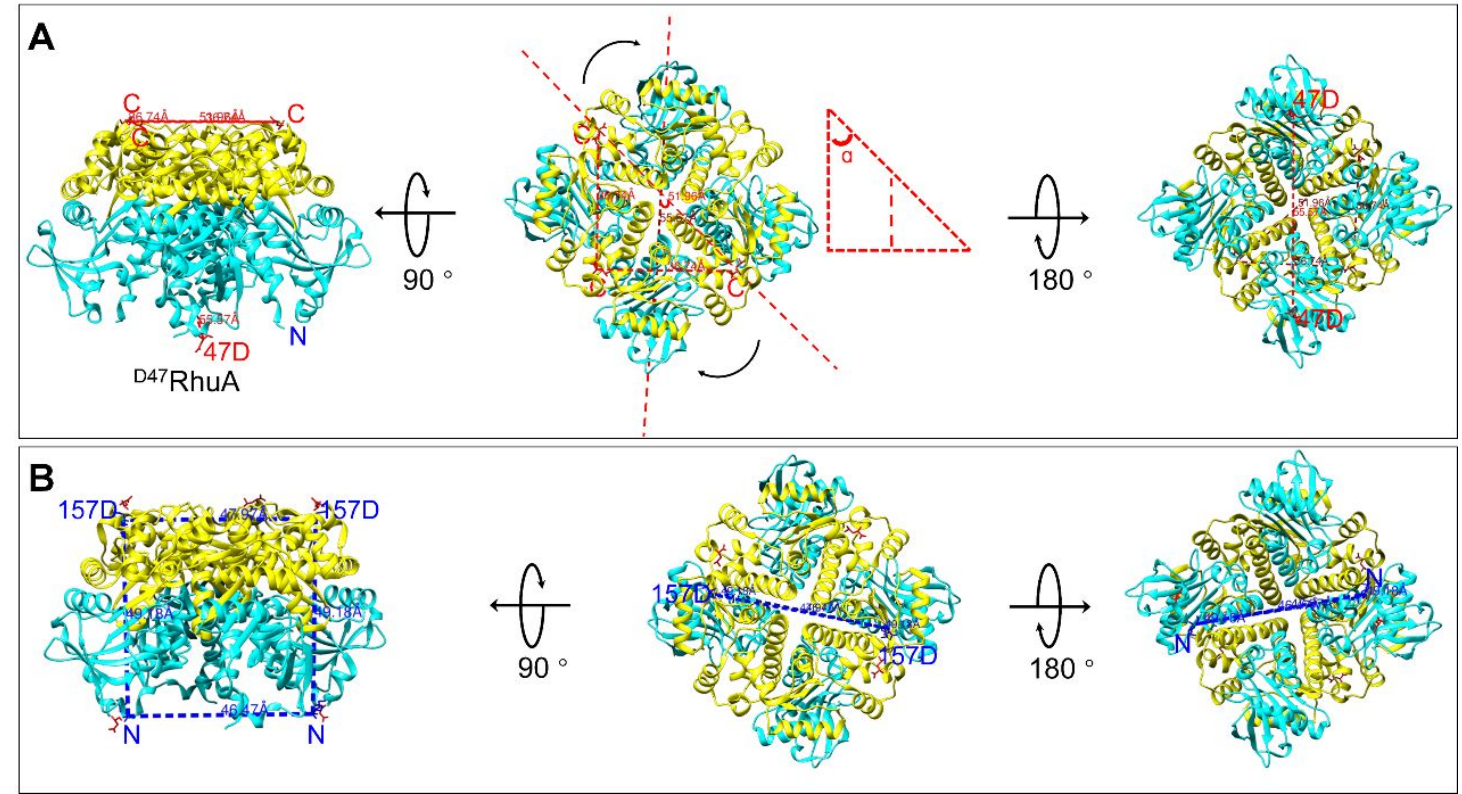

Figure S16. (A) The relative position of Asp47 and C terminal in ${ }^{\mathrm{D} 47}$ RhuA. (B) The relative position of Asp157 and $\mathrm{N}$ terminal in ${ }^{\mathrm{D} 47} \mathrm{RhuA}$. 

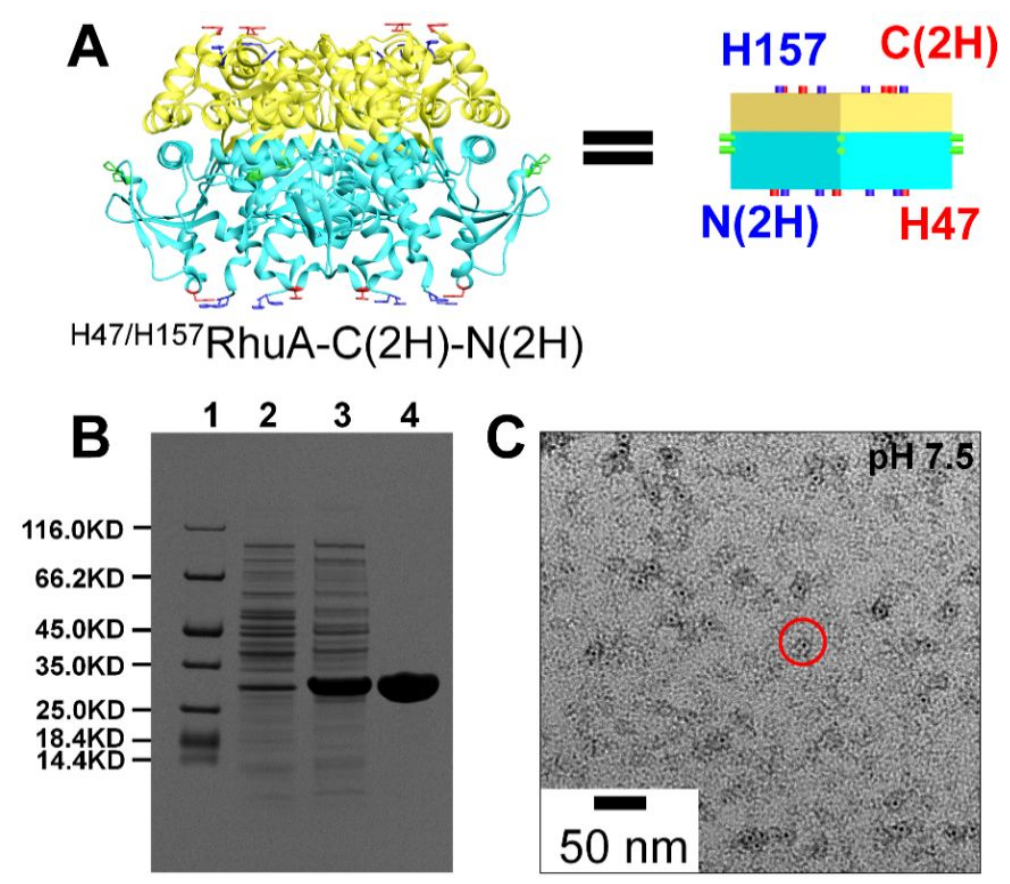

Figure S17. (A) Cartoon, (B) SDS-PAGE, and (C) TEM characterization of ${ }^{\mathrm{H} 47 / \mathrm{H} 157} \mathrm{RhuA}-\mathrm{C}(2 \mathrm{H})-\mathrm{N}(2 \mathrm{H})$.
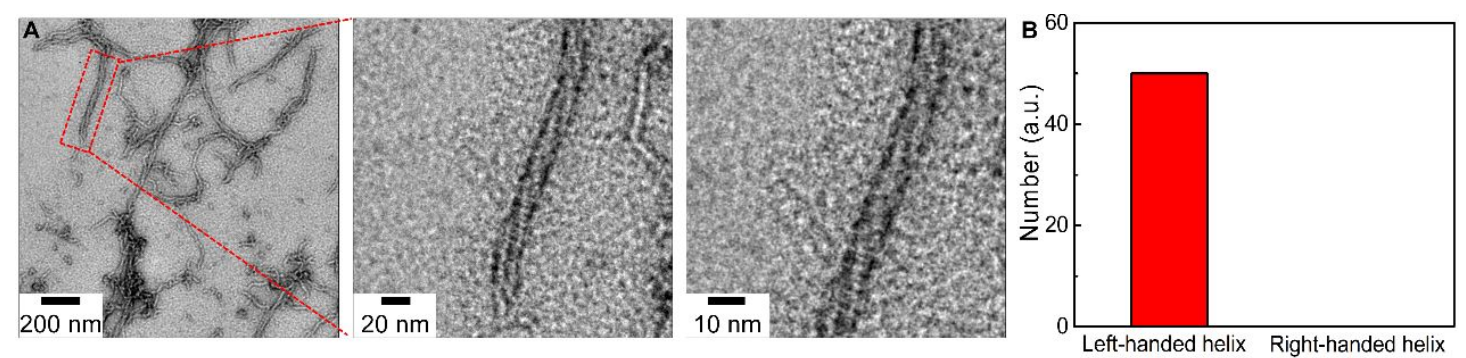

Figure S18. (A) High-resolution TEM image of left-handed double-helical superstructure. (B) The statistics of the chirality of the obtained double-helical superstructures. Data are shown as number $(n=50)$. 


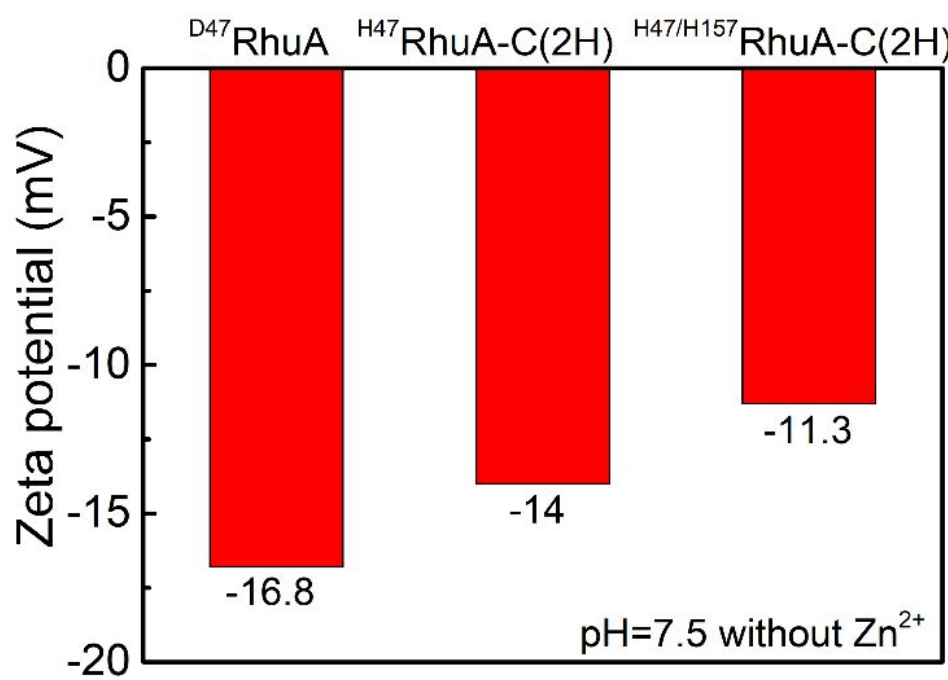

Figure S19. The characterization of zeta potential of ${ }^{\mathrm{D} 47} \mathrm{RhuA}$ (control), ${ }^{\mathrm{H} 47} \mathrm{RhuA}-\mathrm{C}(2 \mathrm{H})$ and ${ }^{\mathrm{H} 47 / \mathrm{H} 157} \mathrm{RhuA}-\mathrm{C}(2 \mathrm{H})-$ $\mathrm{N}(2 \mathrm{H})$ tetramers at $\mathrm{pH}=7.5$ without $\mathrm{ZnCl}_{2}(25 \mu \mathrm{M})$.
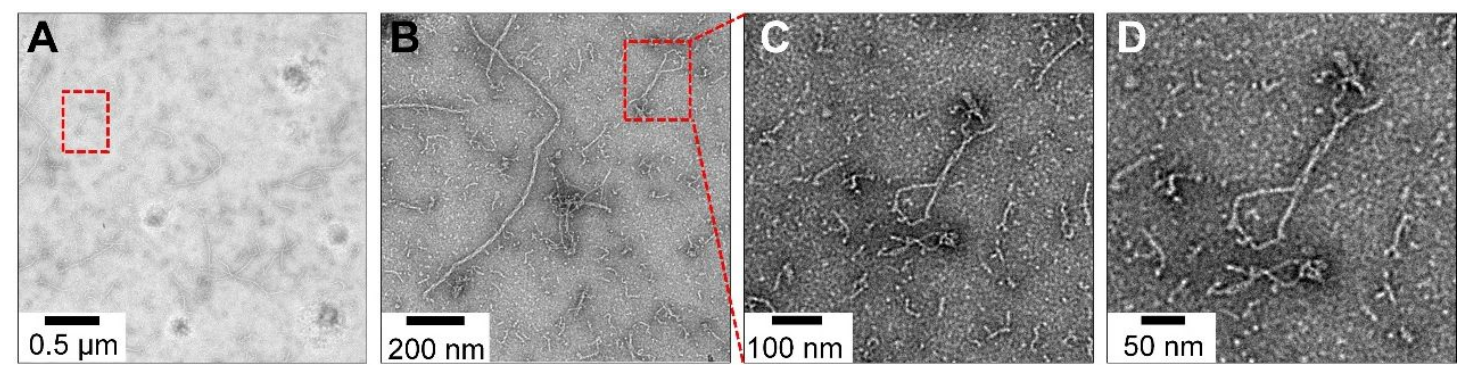

Figure S20. TEM characterization of intermediate state of double-helical superstructures. (A-D) Low- and highresolution TEM images. 

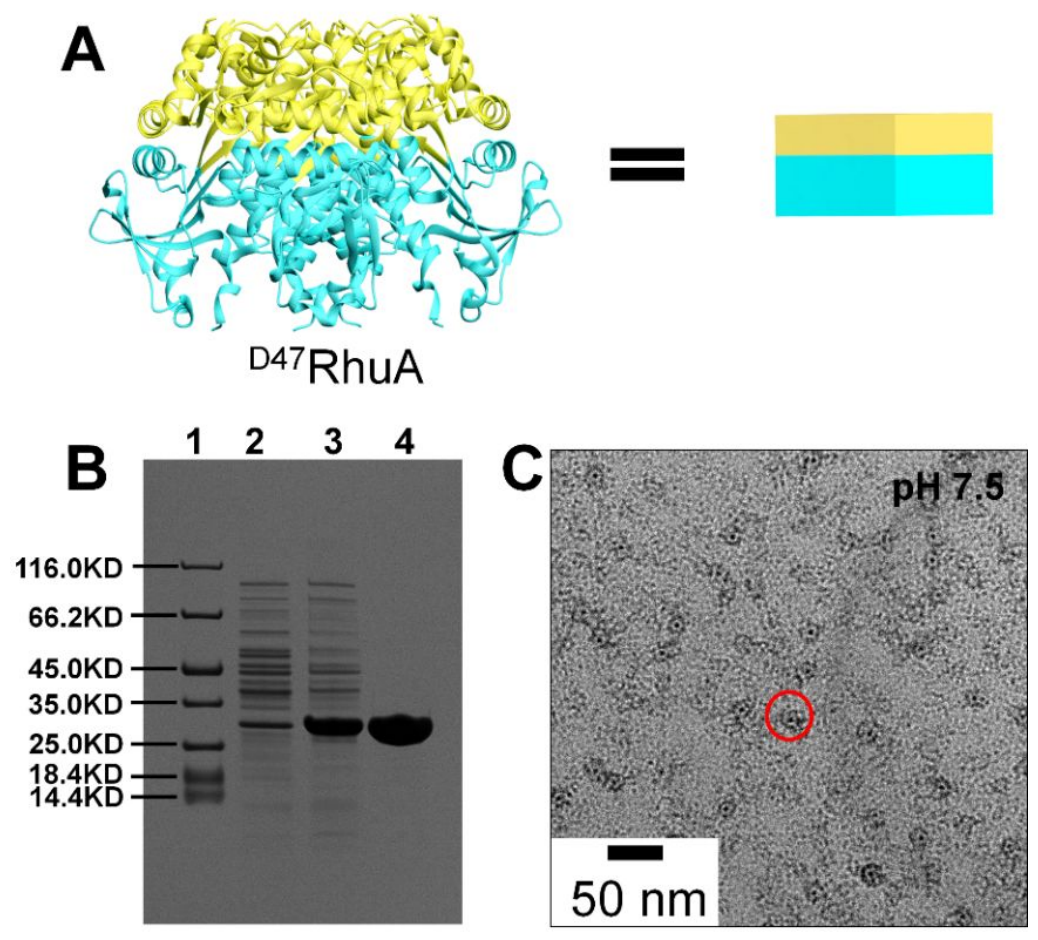

Figure S21. (A) Cartoon, (B) SDS-PAGE, and (C) TEM characterization of ${ }^{\mathrm{D} 47}$ RhuA (control).

\section{REFERENCES}

1. Ringler, P.; Schulz, G. E. Self-Assembly of Proteins into Designed Networks. Science 2003, 302, 106-109.

2. Grueninger, D.; Treiber, N.; Ziegler, M. O. P.; Koetter, J. W. A.; Schulze, M.-S.; Schulz, G. E. Designed Protein-Protein Association. Science 2008, 319, 206-209.

3. Suzuki, Y.; Cardone, G.; Restrepo, D.; Zavattieri, P. D.; Baker, T. S.; Tezcan, F. A. Self-Assembly of Coherently Dynamic, Auxetic, Two-Dimensional Protein Crystals. Nature 2016, 533, 369373.

4. Du, M.; Zhou, K.; Wang, X.; Zhang, J.; Zhang, Y.; Dong, J.; Wu, L.; Qiao, Z.; Chen, G.; Wang, Q. Precise Fabrication of De Novo Nanoparticle Lattices on Dynamic 2D Protein Crystalline Lattices. Nano Lett. 2020, 20, 1154-1160. 